\title{
Land cover map production for Brazilian Amazon using NDVI SPOT VEGETATION time series
}

\author{
A. Rodrigues, A.R.S. Marcal, D. Furlan, M.V. Ballester, and M. Cunha
}

\begin{abstract}
Earth Observation Satellite (EOS) data have a great potential for land cover mapping, which is mostly based on high resolution images. However, in tropical areas the use of these images is seriously limited due to the presence of clouds. This paper evaluates the ability of temporal-based image classification methods to produce land cover maps in tropical regions. A new approach is proposed for land cover classification and updating based exclusively on temporal series data, illustrated with a practical test using SPOT VEGETATION satellite images from 1999 to 2011 for Rondonia (Amazon), Brazil. Using the GLC2000 as reference, a Normalized Difference Vegetation Index (NDVI) time series of 15 distinct land cover classes (LCC) were created. Two classifiers were used (Euclidean Distance and Dynamic Time Warping) to produce maps of land cover changes for 1999-2011. Due to the difficulties in discriminating 15 LCC in the Amazon region, a hierarchical aggregation was performed by joining the initial classes gradually up to four broad classes. The land cover changes in the 1999-2011 period were evaluated using criteria based on the classification results for the individual years. The comparison with reference data showed consistent results, proving that this approach is able to produce accurate land cover maps using exclusively temporal series EOS data.
\end{abstract}

\begin{abstract}
Résumé. Les données des Satellites d'Observation de la Terre ont un grand potentiel pour la cartographie du couvert végétal, la plupart basée sur des images d' haute résolution. Cependant, l'utilisation de ces images en régions tropicales est sérieusement limitée en raison de la présence de nuages. Ce document évalue l'adéquation des méthodes de classification en utilisant des images temporelles pour produire des cartes d'occupation des sols dans les régions tropicales. Une nouvelle approche est proposée pour classification de la couverture terrestre et mises à jour basée uniquement sur des données de séries temporelles, et illustrée par un test pratique en utilisant des données du satellite SPOT VEGETATION entre 1999 et 2011 pour Rondonia (Amazonie), Brésil. En prenant comme référence le GLC2000, ont été créés séries temporelles de NDVI pour 15 différents types de couverture terrestre (TCT). Deux classificateurs ont été utilisé (Distance Euclidienne et «Dynamic Time Warping») pour produire cartes des modifications de la couverture du sol pour le période 1999-2011. Due de la difficulté en classifier 15 TCT en la région de l'Amazonie, une agrégation hiérarchique a été faite en joignant les classes initiales graduellement jusqu'à quatre vaste classes. Les modifications de la couverture terrestre au période de 1999-2011 ont été évaluées par un critère basé sur les résultats de la classification pour chaque année. La comparaison avec les données de référence a montré résultats conformes, ce qui prouve que cette approche est capable de produire exact cartes d'occupation du sol en utilisant exclusivement des données de séries temporelles.
\end{abstract}

\section{Introduction}

The global environmental change research community requires improved and up to date land cover maps at regional to global scales to support a variety of science and policy applications. This is particularly true in the Brazilian Amazon where land cover change induced either by human and natural causes has been unprecedented in recent decades (Alves et al., 2009; Asner et al., 2009; Ballester et al., 2003; Braswell et al., 2003; Brown et al., 2007; Houghton et al., 2000; Li et al., 2012).

While the need for frequent monitoring of land cover changes is clear, it is difficult to produce these maps using only ground-based information (Loveland et al., 2000). The automatic classification of Earth Observation Satellite (EOS) data is thus frequently used for land cover mapping, mostly based on high resolution image data (e.g., from Landsat satellites). The ability to apply automatic classification methods to produce land cover change maps and information, with the range, quality, and detail needed by scientists and resource management, is a huge challenge. This is emphasized in tropical areas where the presence of cloud cover seriously limits the use of passive EOS data (Carreiras et al., 2003). In the case of the Amazon, cloud cover is frequent particularly in the rainy season. To eliminate this limitation, the use of low spatial resolution

Received 30 September 2012. Accepted 31 May 2013. Published on the Web at http://pubs.casi.ca/journal/cjrs on 30 October 2013.

A. Rodrigues ${ }^{1}$ and M. Cunha. Universidade do Porto, Faculdade de Ciências, Centro de Investigação em Ciências Geo-Espaciais - CICGE, Porto, Portugal.

A.R.S. Marcal. Universidade do Porto, Faculdade de Ciências, Departamento de Matemática and INESC TEC, Porto, Portugal.

D. Furlan and M.V. Ballester. Universidade de São Paulo - USP, Centro de Energia Nuclear na Agricultura - CENA, Piracicaba, Brasil.

${ }^{1}$ Corresponding author: (e-mail: dr.arlete@gmail.com). 
EOS data that have a very high acquisition frequency (daily) such as AVHRR (Loveland et al., 2000), SPOT VEGETATION (Carreiras et al., 2003), and MODIS (Wardlow and Egbert, 2008) can be an alternative. However, to better use these data sources, the classification needs to be slightly different than the standard approach. Instead of using a single image, where the multispectral values are used as features for each pixel, the temporal yearly Normalized Difference Vegetation Index (NDVI) profile is used as a feature vector instead.

The aim of this work was to propose a new approach for land cover classification and updates based exclusively on temporal series of NDVI, illustrated with a practical case using SPOT VEGETATION (VGT) satellite data from 1999 to 2011 for Rondonia (Amazon), Brazil. The Global Land Cover Map of the Year 2000 (GLC2000) of South America was used to select 15 distinct land cover classes (LCC) in the SPOT VGT images. Temporal yearly NDVI profiles were extracted for each LCC and a pixel-by-pixel classification was made using the Euclidean Distance (ED) and Dynamic Time Warping (DTW) as classifiers. Two approaches were considered: one that uses the NDVI time series of the reference year (2000) to classify all years; and another that considers the NDVI time series obtained from the year under analysis.

Because of the difficulty in classifying 15 vegetated classes over the Amazon, the 15 initial LCC were aggregated in four main groups based on their NDVI profile similarity. The ED and DTW measures were used to compute a hierarchical aggregation of the initial classes using the method proposed in Rodrigues et al. (2013). The effect of the NDVI time series similarity on the classification results was evaluated by performing a new classification using the four new groups of classes and comparing the results with the land cover maps obtained for the 15 initial classes.

The LCC variability over the years was analyzed by classifying each pixel as "permanent", "stable", "change", "stable in the first years", "stable in the last years", and "unspecified" using a criteria based on the number of identical classes obtained from 1999 to 2011. To evaluate the ED and DTW land cover maps between 2000 and 2011 a comparison was made with the PRODES data (PRODES, 2013) available for 2000 and 2011.

\section{Materials and methods}

\section{Study area}

A test area was established in northwest Brazil, containing the entire state of Rondonia. The transformation of the tropical forests to pastures and crops in western Amazonia, particularly at the Rondonia state, was rapidly developed under a series of government projects for resettling small farmers from southern Brazil (Ballester et al., 2003). These projects resulted in high deforestation rates, which have been well documented since the early 1980s until today through the use of satellite imagery (Alves et al., 1999; INPE, 2000). In this region, deforestation evolution leads to a typical spatial fishbone pattern associated with the colonization process and road development (Dale et al., 1994; Moran, 1993; Pedlowski et al., 1997; Ballester et al., 2003). Large areas of previously untouched rainforest have undergone rapid change since the 1970s due to extensive immigration and colonization. In just 40 years (1970-2010), the population grew from 116 thousand to 1.5 million inhabitants, and the state lost over $34 \%$ of its native forest cover (INPE, 2000). Spatially, the deforestation process is more intense along the highway BR364, between Cuiba and Porto Velho, that was constructed in 1965, improved in 1969 (Fujisaka et al., 1996), and finally paved in 1984. The main land use in the region is cattle pasture, rising from $67 \%$ of the state cultivated area in 1985 to $91 \%$ in 2006 , when perennial and annual crops only accounted for $5 \%$ of agricultural areas of Rondonia, respectively (IBGE, 2013).

The GLC2000 dataset (Eva et al., 2004) was used to establish training sites, characterizing the most relevant land cover classes in this region. Although the GLC2000 map has problems picking up classes over vegetated land surfaces (Eva et al., 2006; Gonsamo and Chen, 2011), it was the only complete land cover map available. The GLC2000 classes were compared with ground reference information acquired for the year 2000. The field data were obtained by recording each point location using a Garmin 76-Map GPS. Each control point was photographed, and land cover at the eight cardinal points was recorded. Figure 1 presents the GLC2000 land map for the central region of Rondonia (left) and the location of the 133 field data points (right). Table 1 presents a comparison between the field and GLC2000 data. The main differences occurred in the urban and water classes, with good agreement for the other classes evaluated. For example, in the GLC2000 the rip and (or) regrowth field classes were assigned to the Agriculture Intensive, Mosaic Agriculture, and (or) Degraded Forest classes, which are crops also characterized by a regrowth around the months of July and August. The results in Table 1 show a coherent correspondence between the two datasets for the majority of the pixels (approximately $88 \%$ ).

The GLC2000 was thus considered as the reference land cover map. For each of the $15 \mathrm{LCC}$ used, a training site was selected carefully to avoid pixel boundaries with other classes. The size of the training sites was, on average, 37 pixels, ranging from 15 to 252 pixels. Table 2 presents the description, number of pixels, and coefficient of variation (Reed et al., 2002) for the NDVI profiles of the pixels assigned to each class. A total of 10 LCC present a coefficient of variation below $10 \%$, with an overall mean of $11.0 \%$ for the 15 classes.

Most sites were identified in the central region of Rondonia, where in the last three decades there has been considerable change in land use and (or) land cover, mostly due to deforestation for crop and grassland production (Eva 


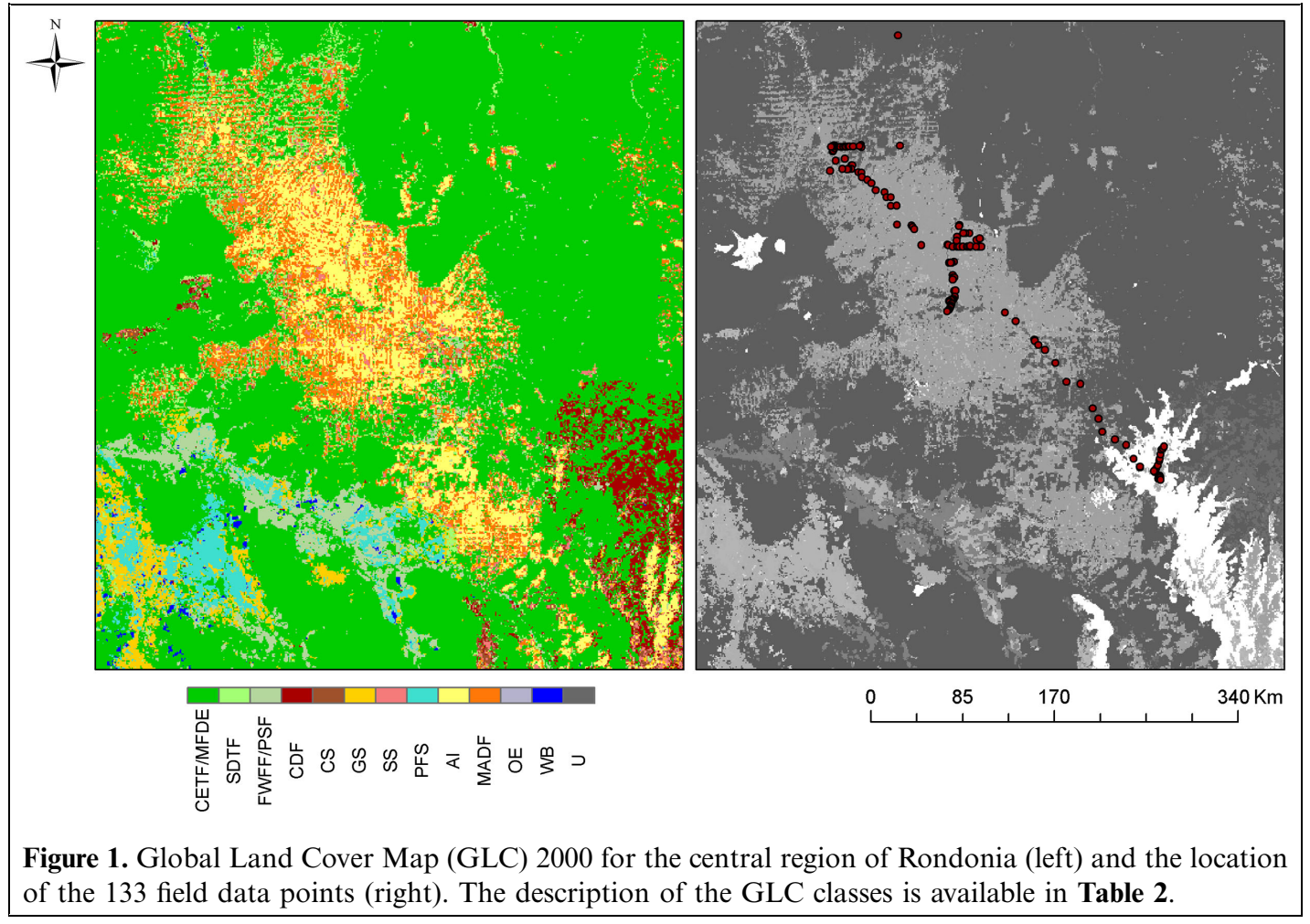

et al., 2002). There are also some areas of transition between forest and regeneration, which were deforested and later abandoned, thus starting a natural regeneration process. The classes were chosen to include native vegetation, regeneration areas, intensive agriculture, flooded vegetation, and urban areas.

The Brazilian Amazon, in particular the state of Rondonia, has only two well-defined seasons: dry and rainy. The start of the dry season may vary from year to year, but it always includes the months of July and August. There is no significant variation of the air temperature throughout the year. Thus the main climatic influence for vegetation development is the annual hydric regime. The average monthly precipitation in the state capital, Porto Velho, for the year 2000 is presented in Figure 2. This plot clearly shows the presence of a dry season, with one month (June) almost without rain. This pluviometric pattern has a great influence in the vegetation development of grassland and shrubland and consequently on the annual pattern of NDVI values.

\section{Satellite imagery and data preprocessing}

The VGT sensor onboard the SPOT4 satellite has provided daily coverage of the entire Earth since 1998, at a spatial resolution of $1 \mathrm{~km}$ (VITO, 2012). It acquires data, which are delivered as primary products or daily (S1) and ten-days (S10) syntheses, in four spectral bands (blue, red, near-infrared and short-wave infrared), ranging from 0.43 to
$1.75 \mu \mathrm{m}$ (VITO, 2012). The NDVI is computed from the extracted pixel values as

$\mathrm{NDVI}=\left(\rho_{\mathrm{NIR}}-\rho_{\mathrm{RED}}\right) /\left(\rho_{\mathrm{NIR}}+\rho_{\mathrm{RED}}\right)$

where $\rho_{\text {NIR }}$ is the reflectance at the near-infrared wavelength band and $\rho_{\text {RED }}$ is the reflectance at the red waveband (Rouse et al., 1973). The widths of the reference bands of the VGT sensor are $0.61-0.68 \mu \mathrm{m}$ (RED) and $0.78-0.89 \mu \mathrm{m}$ (NIR).

Ten-day NDVI synthesis images (NDVI S10) are available from VGT globally and are divided into 10 regions, one of them being South America. These synthesis images are Maximum Value Composites (MVCs) of daily NDVI images, intended to reduce the noise caused by a variety of biophysical factors. For each year, a total of 36 VGT NDVI S10 images are available (three for each month).

The entire training area for each of the $15 \mathrm{LCC}$ was considered as a unit instead of using a pixel-by-pixel approach. The median of the NDVI S10 values of the pixels assigned for each class were computed. The yearly NDVI time series were created using the median values obtained for each of the 36 images available in one year.

\section{Image classification procedure}

The land cover classification of a pixel makes use of its NDVI annual profile (time series). The pixel-by-pixel classification process applied in this work compares the annual NDVI pixel profile with each of the 15 reference time series (15 NDVI class profiles). The class label of the most 
Table 1. Land cover comparison between field data and Global Land Cover Map for the year 2000.

\begin{tabular}{|c|c|c|c|}
\hline \multicolumn{2}{|c|}{ Field data } & \multicolumn{2}{|l|}{ GLC2000 } \\
\hline Class & $\begin{array}{c}\text { Pixels } \\
\text { (no.) }\end{array}$ & Class & $\begin{array}{c}\text { Pixels } \\
\text { (no.) }\end{array}$ \\
\hline \multirow[t]{3}{*}{ Crop } & 26 & $\begin{array}{l}\text { Agriculture/mosaic } \\
\text { agriculture }\end{array}$ & 16 \\
\hline & & $\begin{array}{l}\text { Mosaic forest/dense } \\
\text { evergreen }\end{array}$ & 3 \\
\hline & & Shrublands & 7 \\
\hline \multirow[t]{4}{*}{ Forest } & 10 & $\begin{array}{l}\text { Mosaic agriculture/ } \\
\text { degraded forest }\end{array}$ & 5 \\
\hline & & $\begin{array}{l}\text { Closed evergreen tropical } \\
\text { forest }\end{array}$ & 3 \\
\hline & & Agriculture intensive & 1 \\
\hline & & $\begin{array}{l}\text { Semideciduous transition } \\
\text { forest }\end{array}$ & 1 \\
\hline Next to forest & 10 & Next to forest & 10 \\
\hline \multirow[t]{2}{*}{ Pasture } & 28 & Agriculture intensive & 20 \\
\hline & & $\begin{array}{c}\text { Mosaic agriculture/ } \\
\text { degraded forest }\end{array}$ & 8 \\
\hline \multirow[t]{2}{*}{ Rip/regrowth } & 33 & Agriculture intensive & 22 \\
\hline & & $\begin{array}{c}\text { Mosaic agriculture/ } \\
\text { degraded forest }\end{array}$ & 11 \\
\hline \multirow[t]{3}{*}{ Shrublands } & 8 & Shrub savannah & 1 \\
\hline & & Shrublands & 5 \\
\hline & & $\begin{array}{l}\text { Mosaic agriculture/dense } \\
\text { forest }\end{array}$ & 2 \\
\hline $\begin{array}{l}\text { Forest and shrub } \\
\text { (burnt) }\end{array}$ & 2 & Agriculture intensive & 2 \\
\hline \multirow[t]{4}{*}{ Water } & 4 & Shrub savannah & 1 \\
\hline & & $\begin{array}{l}\text { Closed evergreen tropical } \\
\text { forest }\end{array}$ & 1 \\
\hline & & $\begin{array}{l}\text { Semideciduous transition } \\
\text { forest }\end{array}$ & 1 \\
\hline & & Agriculture intensive & 1 \\
\hline \multirow[t]{5}{*}{ Urban } & 12 & Urban & 5 \\
\hline & & Agriculture intensive & 2 \\
\hline & & Grass savannah & 1 \\
\hline & & $\begin{array}{c}\text { Mosaic agriculture/ } \\
\text { degraded forest }\end{array}$ & 3 \\
\hline & & Shrub savannah & 1 \\
\hline
\end{tabular}

similar reference profile is retained for the pixel under analysis. To compare the NDVI time series, the ED (Agrawal et al., 1993) and DTW (Berndt and Clifford, 1994; Chu et al., 2002) similarity measures were used. These measures were selected as they are the commonly used algorithms for similarity analysis of time series (Agrawal et al., 1995; Das et al., 1998; Debregeas and Hebrail, 1998; Faloutsos et al., 1994; Keogh et al., 2001). Furthermore, these distance measures have important differences when comparing time series data. The ED is a time-rigid measure and does not consider any distortions or shifts over time, whereas the DTW is a time-flexible measure capable to consider the shifts and distortions over time, which can have an important role in vegetation dynamics. To test the
Table 2. Characterization of the land cover classes.

\begin{tabular}{llcc}
\hline Land cover description & Acronym & $\begin{array}{c}\text { Pixels } \\
\text { (no.) }\end{array}$ & $\begin{array}{c}\text { Coefficient of } \\
\text { variation (\%) }\end{array}$ \\
\hline Agriculture Intensive & AI & 35 & 6.0 \\
Closed Deciduous Forest & CDF & 16 & 9.8 \\
Closed Evergreen Tropical & CETF & 252 & 8.6 \\
$\quad$ Forest & CS & 16 & 9.1 \\
Closed Shrublands & FWFF & 48 & 20.3 \\
Fresh Water Flooded & & & \\
$\quad$ Forest & GS & 30 & 10.2 \\
Grass Savannah & MADF & 16 & 7.6 \\
Mosaic Agriculture - & & & \\
$\quad$ Degraded Forest & MFDE & 24 & 8.5 \\
Montane Forest (500- & & & \\
$\quad$ 1000m) - Dense & & & \\
$\quad$ Evergreen & OE & 15 & 10.7 \\
Ore Exploration & PFS & 16 & 7.4 \\
Periodically Flooded & & & \\
$\quad$ Savannah & PSF & 16 & 5.6 \\
Permanent Swamp Forest & SDTF & 16 & 5.8 \\
SemiDeciduous Transition & SD & & \\
$\quad$ Forest & SS & 16 & 7.7 \\
Shrub Savannah & U & 15 & 12.7 \\
Urban & WB & 20 & 35.3 \\
Water Bodies & & & \\
\hline
\end{tabular}

impacts of temporal distortions, the DTW was applied

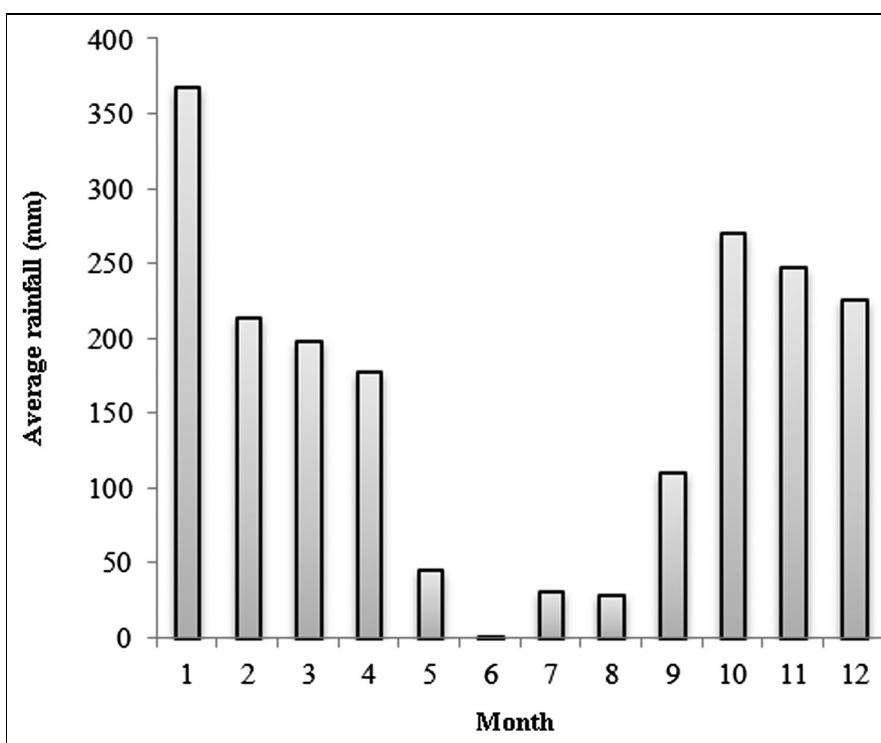

Figure 2. Average monthly rainfall $(\mathrm{mm})$ for Porto Velho (Santo Antônio), for the year 2000. Source: Agência Nacional de Água (ANA).

using a window restriction of 20 days (Berndt and Clifford, 1994) in the time axis (shift).

The 15 reference LCC selected in 2000 were also selected for the remaining years (1999 and 2001-2011). For each year, two classified images were computed using the ED and DTW as classifiers. To evaluate the influence of temporal land cover variability, two approaches were considered: one that establishes the reference NDVI time series of each year 
Table 3. Criteria to define an attribute for each pixel, according to the classification results from 1999 to 2011.

\begin{tabular}{|c|c|}
\hline $\begin{array}{l}\text { Classification } \\
\text { attribute }\end{array}$ & Criteria \\
\hline 1 - Permanent & $11+$ years (out of 13 ) with the same class \\
\hline 2 - Stable & $\begin{array}{l}4+\text { in the first } 5 \text { years and } 4+\text { in the last } \\
5 \text { years classified in the same class }\end{array}$ \\
\hline 3 - Change & $\begin{array}{l}4+\text { in the first } 5 \text { years classified in the same } \\
\text { class } \mathrm{Cl1} \text {, and } 4+\text { in the last } 5 \text { years } \\
\text { classified in the same class } \mathrm{Cl} 2 \text {. } \\
\mathrm{Cl} 1 \neq \mathrm{Cl} 2\end{array}$ \\
\hline $\begin{array}{l}4-\text { Stable in the first } \\
\text { years }\end{array}$ & $\begin{array}{l}4+\text { in the first } 5 \text { years classified in the same } \\
\text { class }\end{array}$ \\
\hline $\begin{array}{l}5-\text { Stable in the last } \\
\text { years }\end{array}$ & $\begin{array}{l}4+\text { in the last } 5 \text { years classified in the same } \\
\text { class }\end{array}$ \\
\hline 6 - Unspecified & None of the previous assignments \\
\hline
\end{tabular}

to process the classification, and another that uses the NDVI profiles identified on the reference year (2000) to classify every year.

The effect of the NDVI time series similarity on the classification results was evaluated, reducing the number of initial LCC and analyzing the land cover variability for each pixel over the years 1999-2011. A hierarchical aggregation of the initial classes was performed using the ED and DTW distance measures, following the method proposed in Rodrigues et al. (2013), and a new classification was made using the new groups of classes. To analyze the LCC variability over years, each pixel was classified as permanent, stable, change, stable in the first years, stable in the last years, and unspecified using the criteria presented in Table 3. These criteria are based on the number of identical classes obtained from 1999 to 2011. Figure 3 presents a schematic illustration of the criteria used, where each color represents a distinct LCC.

To evaluate the consistency of the ED and DTW land cover maps for 2000 and 2011 a comparison was made with the PRODES data available for 2000 and 2011. PRODES (Amazon Deforestation Monitoring Project) consists of a systematic monitoring of deforestation in Amazon, using remote sensing images and digital image processing techniques (PRODES, 2013). ED and DTW maps were reclassified in three main classes: forest, nonforest, and hydrography. The percentage of pixels classified in each class was determined and the consistency of the results was evaluated using the PRODES data as reference.

\section{Results and discussion}

NDVI S10 images from SPOT VGT from 1999 to 2011 were processed for Rondonia. As precipitation has considerable influence on the vegetation development, the most relevant period for this region is from April to September. Furthermore, the presence of clouds limits the use of satellite data in the rainy season. Maximum Value Composite images of January and April-September using NDVI VGT data from 2000 are presented in Figure 4. Due to the frequent cloud cover, the NDVI values from January might not be clearly related to the vegetation type and condition. In the remaining images, it was noticeable that the central areas of Rondonia have lower NDVI values. This is because this part of the state has low height herbaceous or semiherbaceous vegetation, as the soil is mostly used for agriculture and pasture. Moreover, Rondonia is a remarkable example of land cover change in the past decades as a result of deforestation induced by human and natural causes. The converted forest cover in a fishbone pattern, mainly due to forestation caused by agricultural and urban expansion as reported by Eva et al. (2002), is noticeable in Figure 4. The least influence of clouds occurred between June and August. During this period a large increase in NDVI occurred, especially in forests. The better transparency of the atmosphere at this time of the year promotes a net balance of radiation greater than the other parts of the year (Da Rocha et al., 2004; Malhi et al., 2002). This high availability of energy and the ability of forestry trees to capture water from deep soil explain the trend of the NDVI increase in forest areas between June and August.

The original (dotted line) and Savitzky-Golay (Press et al., 2007) smoothed (solid line) NDVI time series training profiles of the 15 LCC, for the year 2000, are presented in Figure 5. Each LCC multitemporal NDVI signature is consistent with its expected pattern of vegetation dynamics

\begin{tabular}{|c|c|c|c|c|c|c|c|c|c|c|c|c|c|c|}
\hline Year & 1999 & 2000 & 2001 & 2002 & 2003 & 2004 & 2005 & 2006 & 2007 & 2008 & 2009 & 2010 & 2011 & Attribute \\
\hline Class & & & & & & & & & & & & & & Permanent \\
\hline Class & & & & & & & & & & & & & & Stable \\
\hline Class & & & & & & & & & & & & & & Change \\
\hline Class & & & & & & & & & & & & & & Stable in the first years \\
\hline Class & & & & & & & & & & & & & & Stable in the last years \\
\hline Class & & & & & & & & & & & & & & Unspecified \\
\hline
\end{tabular}



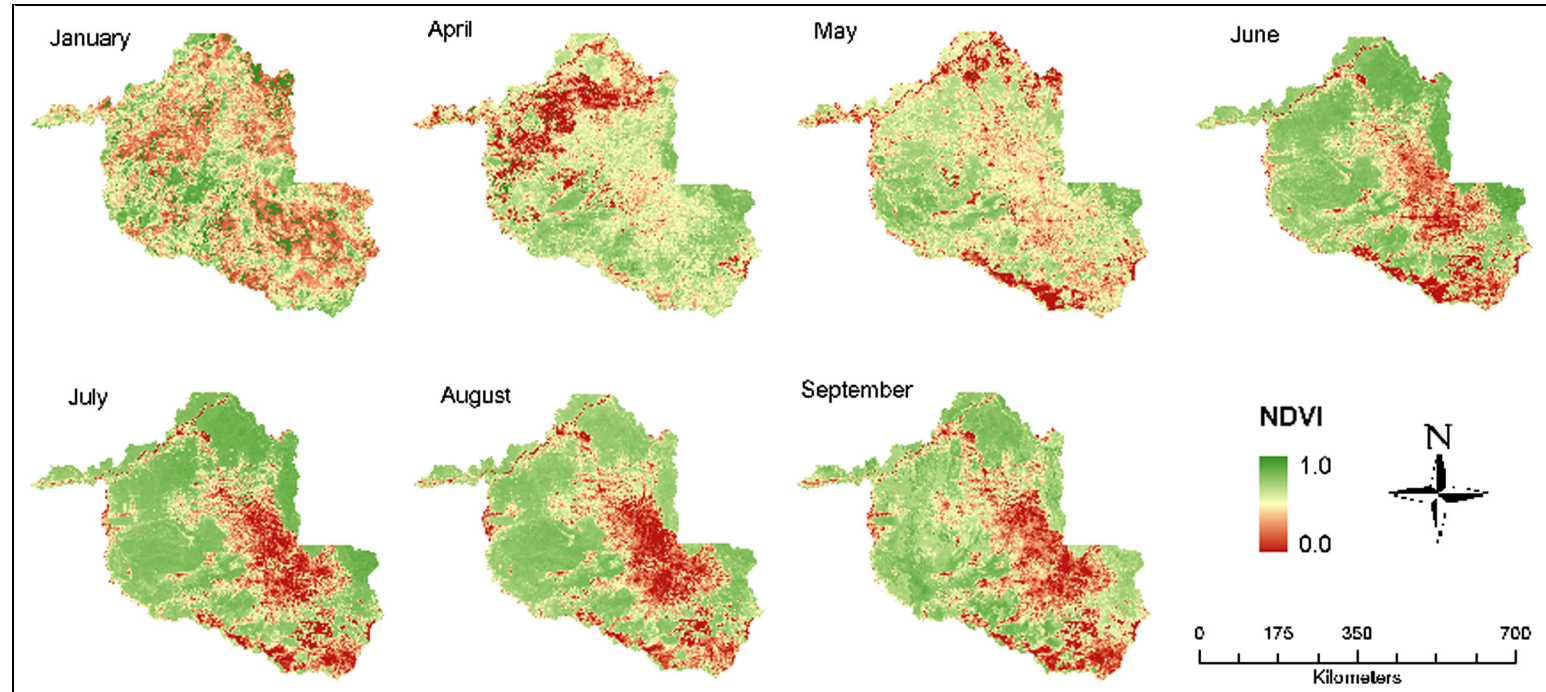

Figure 4. NDVI 10-day composites for Rondonia produced from SPOT VEGETATION data for the year 2000. The NDVI values correspond to the first 10 days of each month.
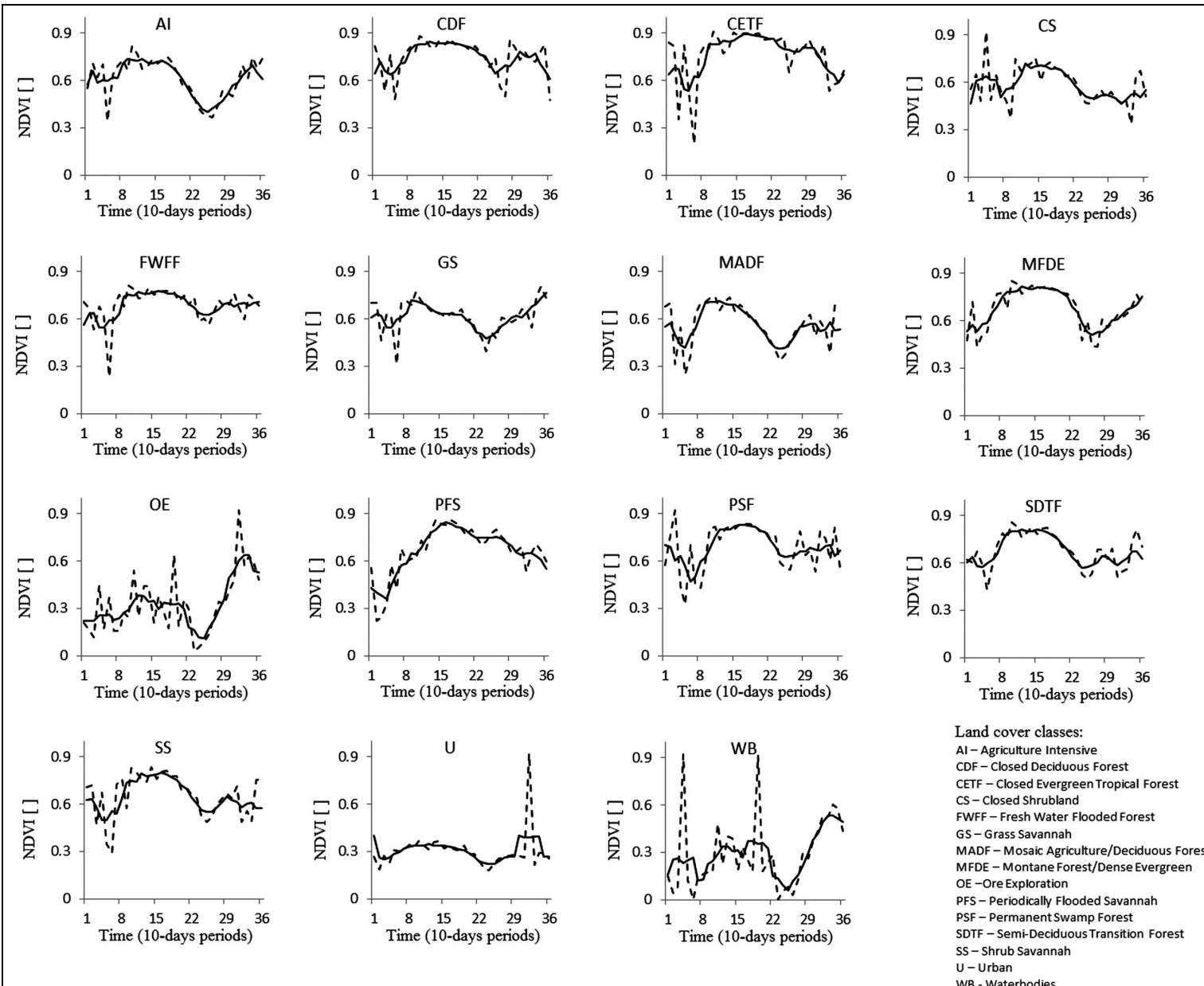

Figure 5. Original (dotted line) and Savitzky-Golay smoothed (solid line) NDVI time series of the 15 land cover classes in Rondonia for the year 2000. 
and most of them are spectrally separable at some point during the growing season. The NDVI profiles consistently showed a major influence of the presence of clouds, especially from November to February. Land cover classes representing shorter vegetation types were the most sensitive to the hydrological regime. The Agriculture Intensive (AI) class showed a decreased NDVI value from June until August, a period that is considered quite dry. Taller vegetation types (e.g., Closed Evergreen Tropical Forest (CETF)) maintained NDVI values above 0.8 from May to September. These higher NDVI values during the dry season could be related with the ability of vegetation to capture depth water.

The NDVI time series training profiles show a considerable similarity among a number of classes (Figure 5), which naturally influences the classification results. Figure 6 presents the classified images for the reference year (2000) using the ED and DTW classifiers. The majority of Rondonia was classified in both images as CETF. Large differences between ED and DTW were obtained in the eastern region of Rondonia: the AI and Grass Savannah (GS) classes were dominant using the ED classifier, but when using the DTW, only the AI could be well distinguished. Some of the pixels that were classified as GS using the ED classifier were classified as Closed Shrublands (CS) using the DTW. This is because these two classes were composed predominantly of grasses and shrubs. The GS class is very dependent on water availability and is characterized by open canopy with herbaceous soil vegetation, whereas the CS class is characterized by shrubs, herbs, and grasses as dominant vegetation, and this vegetation can remain stable over time or can be affected by factors such as fire or browsing. In both cases, the GS and CS classes presented a similar profile in the main growing season (Figure 5), and they can present a double growth due to the herbaceous soil vegetation growth, animal grazing, human interference, or other adverse conditions such as fire.
In the western region of Rondonia another difference can be easily observed between the ED and DTW images: some of the pixels that were classified as CETF using the ED classifier were classified as Montane Forest - Dense Evergreen (MFDE) using the DTW. This can be explained because CETF and MFDE are two classes of large evergreen forest vegetation, presenting high NDVI values and a stable behavior in the main growth season.

\section{Using the profiles from the year under evaluation}

The classified images for 1999, 2000, and 2011 using the ED and DTW classifiers are presented in Figure 7; 1999 presented better results with the reference year (2000) than 2011. The percentage of pixels that suffered changes between 1999 and 2000 (49\% for ED and 57\% for DTW) was lower compared with changes that occurred between 2000 and 2011 (66\% for ED and $72 \%$ for DTW). This can be explained because larger temporal distance will, in general, correspond to higher land cover variability, resulting in higher differences in the classification results.

Table 4 presents the fraction of pixels with different classification results in consecutive years. For both classifiers, the most similar years were found to be 1999 and 2000 . However, the maximum change between consecutive years occurred in different dates for ED (2001-2002) and DTW (2006-2007). The average fraction of pixels that changed between consecutive years was about $70 \%$ for both classifiers considering 15 LCC.

\section{Using the profiles from the year 2000}

Figure 8 shows the classified images for 1999, 2000, and 2011 using the ED and DTW classifiers and the reference signatures from 2000 . Using the ED, $46 \%$ and $47 \%$ of pixels

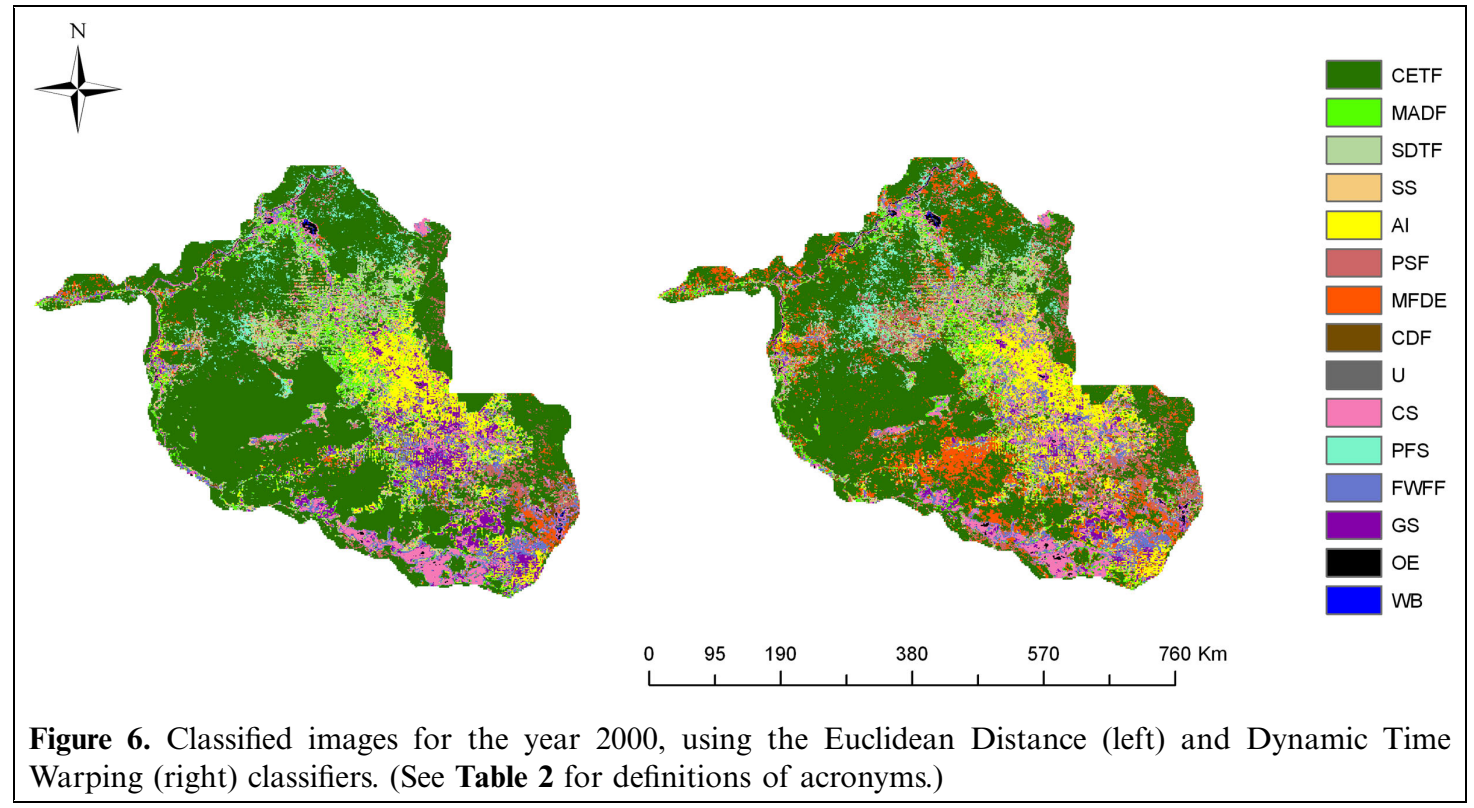




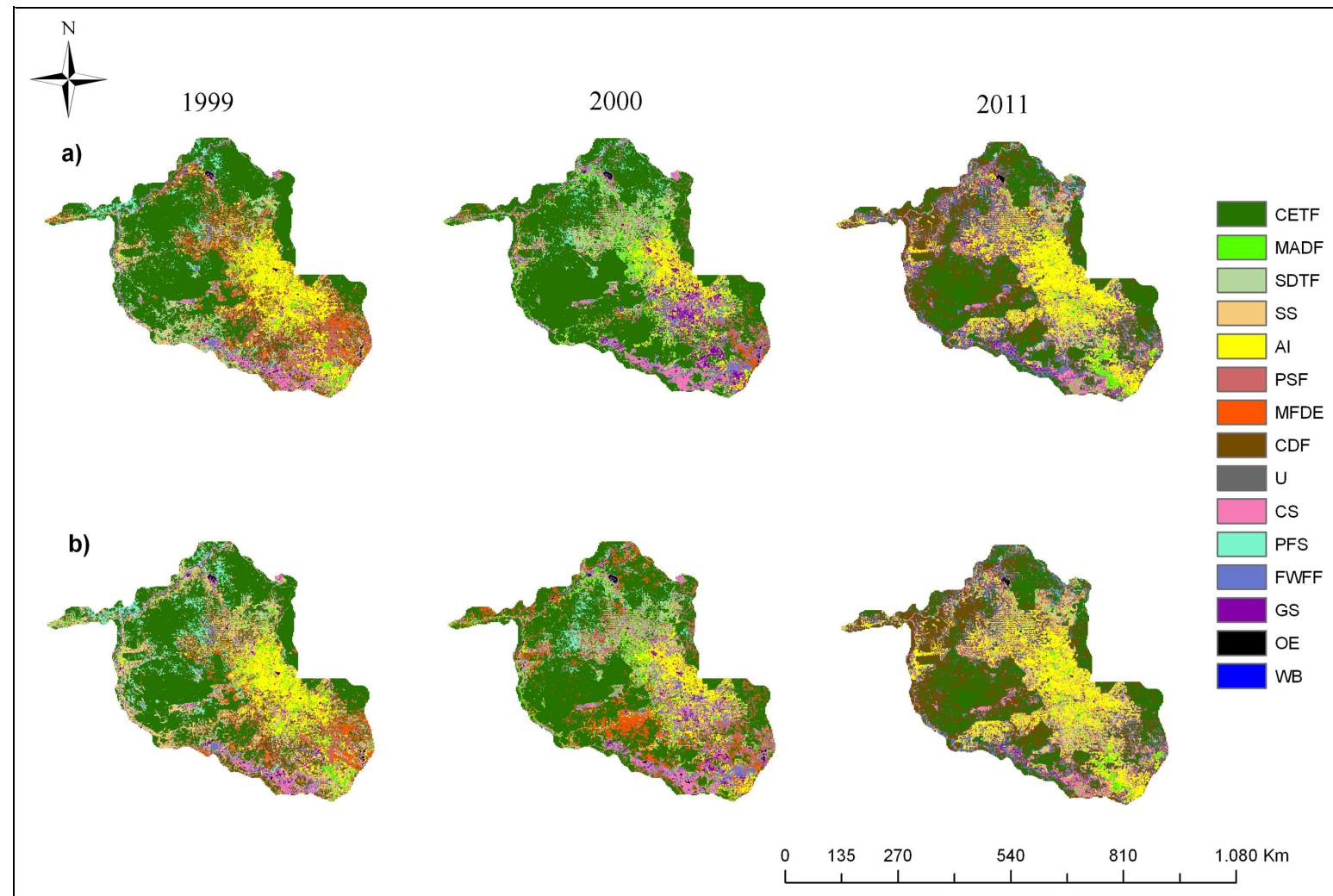

Figure 7. Classified images obtained for 1999, 2000, and 2011 using (a) Euclidean Distance and (b) Dynamic Time Warping as classifiers. (See Table 2 for definitions of acronyms.)

Table 4. Fraction of pixels (\%) that present different classification results between consecutive years.

\begin{tabular}{lccccc}
\hline & \multicolumn{2}{c}{$\begin{array}{c}\text { Profiles from the year } \\
\text { under analysis }\end{array}$} & & \multicolumn{2}{c}{ Profiles from 2000 } \\
\cline { 2 - 3 } \cline { 5 - 6 } Years & $\begin{array}{c}\text { ED } \\
\text { classifier }\end{array}$ & $\begin{array}{c}\text { DTW } \\
\text { classifier }\end{array}$ & & $\begin{array}{c}\text { ED } \\
\text { classifier }\end{array}$ & $\begin{array}{c}\text { DTW } \\
\text { classifier }\end{array}$ \\
\hline $1999-2000$ & 49 & 57 & & 46 & 50 \\
$2000-2001$ & 71 & 75 & & 70 & 66 \\
$2001-2002$ & 78 & 73 & & 64 & 69 \\
$2002-2003$ & 75 & 74 & & 53 & 63 \\
$2003-2004$ & 73 & 71 & & 45 & 63 \\
$2004-2005$ & 74 & 69 & & 38 & 54 \\
$2005-2006$ & 73 & 75 & & 57 & 56 \\
$2006-2007$ & 74 & 77 & & 63 & 62 \\
$2007-2008$ & 66 & 68 & & 67 & 64 \\
$2008-2009$ & 71 & 72 & & 62 & 56 \\
$2009-2010$ & 74 & 68 & & 46 & 47 \\
$2010-2011$ & 60 & 62 & & 39 & 45 \\
\hline
\end{tabular}

Note: ED, Euclidean Distance; DTW, Dynamic Time Warping.

were found to change between 1999 and 2000 and between 2000 and 2011, respectively. Comparing this with the results obtained in the previous approach, the ED can reduce the fraction of pixels with changes between 1999 and 2000 by 3\% and by $19 \%$ between 2000 and 2011 . The DTW using profiles from 2000 also indicated less pixel changes (by $7 \%$ and $14 \%$ ) between 1999 and 2000 and between 2000 and 2011.
Table 4 presents the fraction of pixels that have different classification results between consecutive years, using the reference signatures from 2000. Compared with the results obtained in the previous approach, the use of the 2000 profiles provided a higher correlation between images of two consecutive years and indicated a reduction on the average fraction of pixels with changes $(16 \%$ for ED and $12 \%$ for DTW).

\section{Effect of the NDVI time series similarity on the classification results}

The two previous approaches indicated a considerable variability in LCC over the range of years tested. However, it is worth noting the large number of classes considered and the similarity between some of NDVI time series profiles used to train the LCC (Figure 5). To test the effect of the NDVI time series similarity on the classification results, the 15 LCC were reduced by joining the most similar classes. A hierarchical aggregation, based on the LCC similarity, was done using the ED and DTW measures (Figure 9). Through the dendogram analysis presented in Figure 9, it was possible to clearly identify four groups (A, B, C, and D). Group A contains four classes (2 (Mosaic Agriculture Degraded Forest (MADF)), 3 (SemiDeciduous Transition Forest (SDTF)), 4 (Shrub Savannah (SS)) and 8 (Closed Deciduous Forest (CDF)), the group B contains four classes 


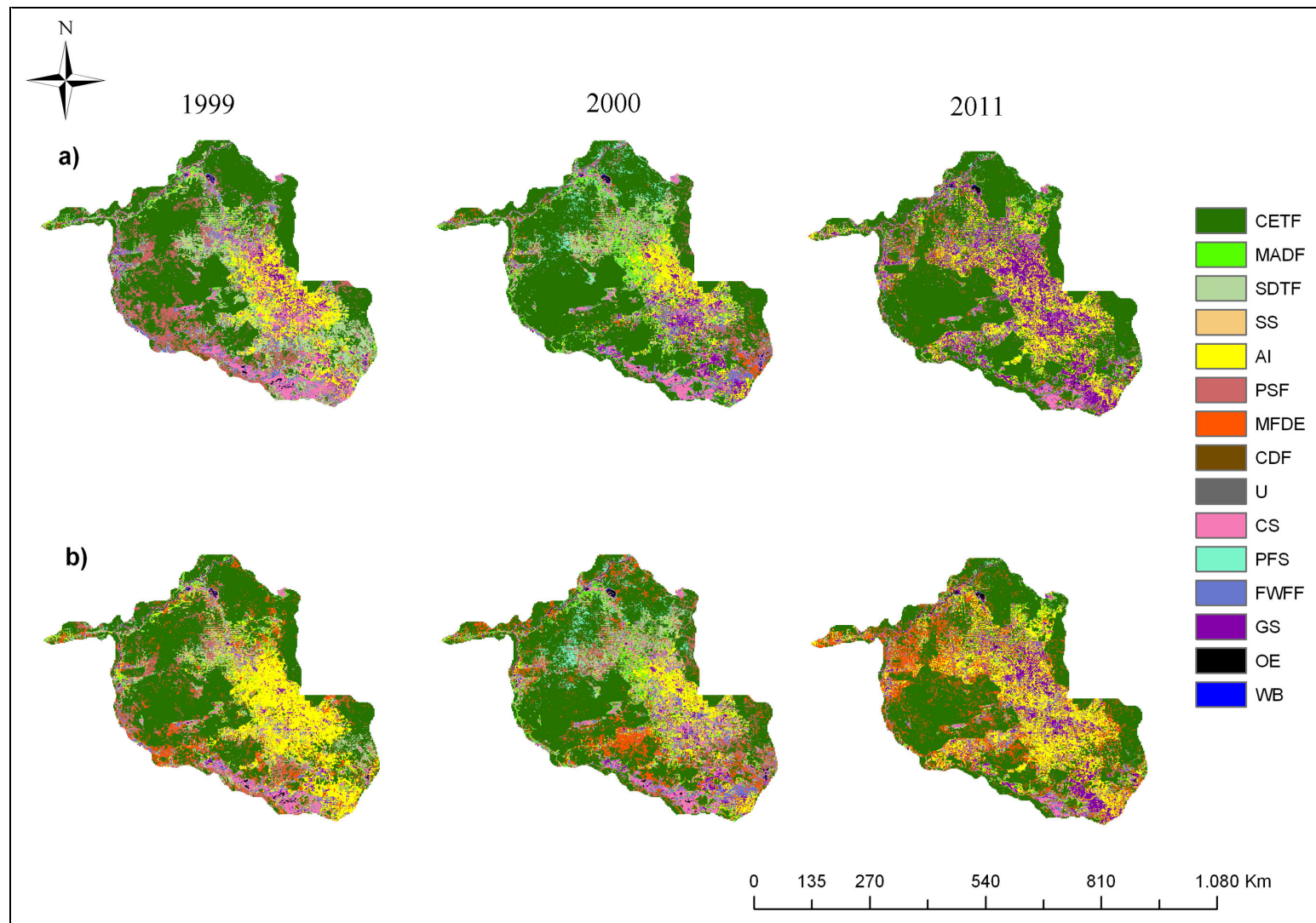

Figure 8. Classified images obtained for 1999, 2000, and 2011 using (a) Euclidean Distance and (b) Dynamic Time Warping as classifiers, and using the profiles of the reference year. (See Table $\mathbf{2}$ for definitions of acronyms.)

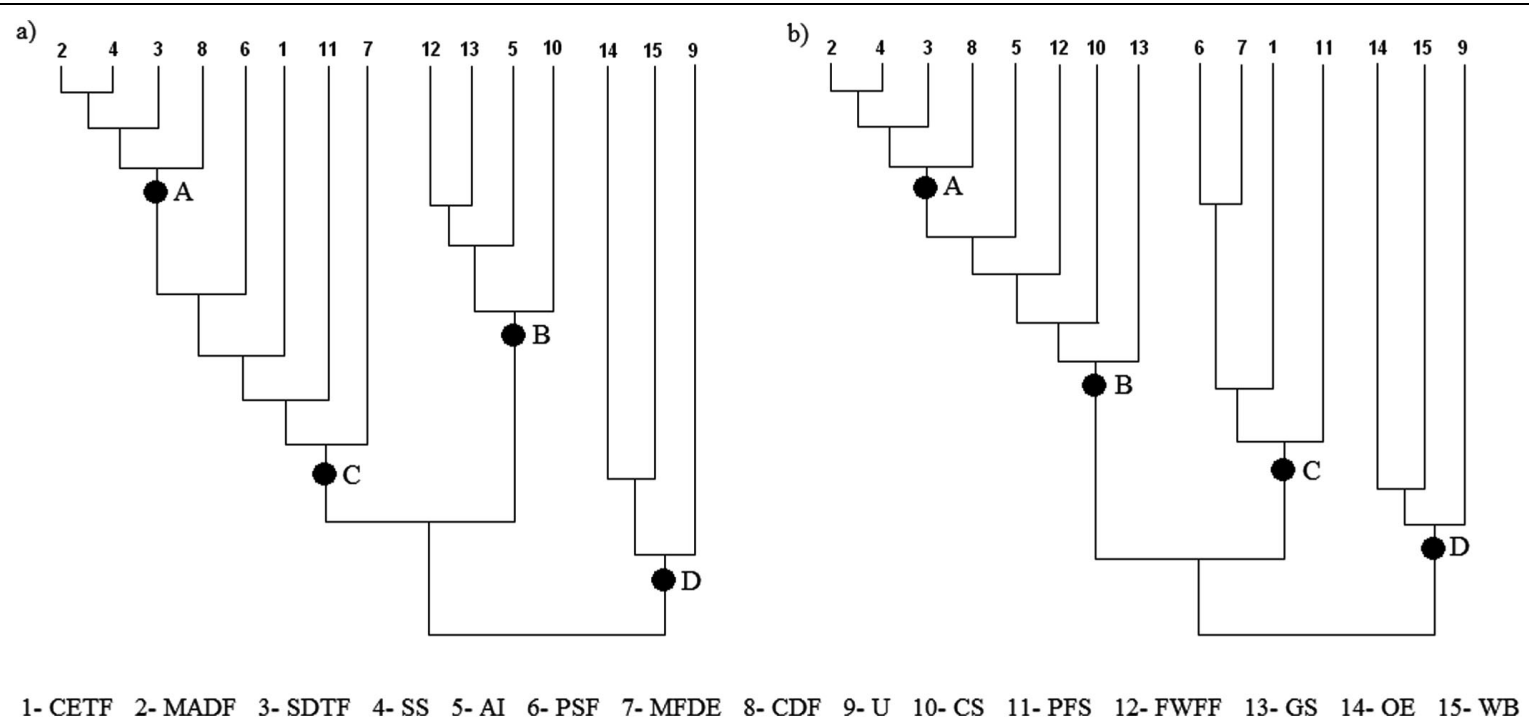

Figure 9. Dendograms for the hierarchical aggregation of the 15 land cover classes, based on the VGT data from 2000, using (a) the Euclidean Distance and (b) Dynamic Time Warping. (See Table 2 for definitions of acronyms.)

(5 (AI), 10 (CS), 12 (Fresh Water Flooded Forest (FWFF)) and $13(\mathrm{GS}))$, and the group $\mathrm{C}$ also four classes (1 (CETF), 6 (Permanent Swamp Forest (PSF)), 7 (MFDE) and 11 (Periodically Flooded Savannah (PFS))). Group D contains the three classes with lower NDVI (9 (Urban (U)), 14 (Ore Exploration (OE)) and 15 (Water Bodies (WB))).
Each of the classified images was reclassified using the approaches presented in the two previous sections, replacing each pixel class by the number of the enclosing group (from 1 to 4, corresponding to A-D). A pixel-by-pixel analysis was made to evaluate the land cover variability over the 13-year period (1999-2011). Each pixel was classified as 
permanent, stable, change, stable in the first years, stable in the last years, and unspecified using the criteria presented in Table 3 and Figure 3.

Table 5 presents a comparison between the ED classification results for four distinct pixels (P1, P2, P3, P4), using the 15 initial LCC and the four groups of classes. Using 15 classes, P1 and P2 presented a total of five distinct LCC over the 13 years, and $\mathrm{P} 4$ presented the lower land cover variability with a total of three LCC. Although a pixel can present higher land cover variability over the years, this does not imply a greater deviation between the land cover profiles. For example, P1 and P3 had an initial number of five and four distinct LCC, respectively, but using the

Table 5. Classification results for four distinct pixels (P1, P2, P3, P4) from 1999 to 2011 using the Euclidean Distance.

\begin{tabular}{|c|c|c|c|c|c|c|c|c|}
\hline \multirow[b]{2}{*}{ Year } & \multicolumn{4}{|c|}{15 classes } & \multicolumn{4}{|c|}{4 classes } \\
\hline & $\mathrm{P} 1$ & $\mathrm{P} 2$ & P3 & P4 & P1 & $\mathrm{P} 2$ & P3 & P4 \\
\hline 1999 & 11 & 1 & 1 & 1 & 3 & 3 & 3 & 3 \\
\hline 2000 & 1 & 1 & 6 & 1 & 3 & 3 & 3 & 3 \\
\hline 2001 & 11 & 7 & 11 & 11 & 3 & 3 & 3 & 3 \\
\hline 2002 & 8 & 8 & 11 & 11 & 1 & 1 & 3 & 3 \\
\hline 2003 & 7 & 7 & 11 & 1 & 3 & 3 & 3 & 3 \\
\hline 2004 & 7 & 11 & 6 & 1 & 3 & 3 & 3 & 3 \\
\hline 2005 & 6 & 7 & 1 & 6 & 3 & 3 & 3 & 3 \\
\hline 2006 & 1 & 7 & 6 & 6 & 3 & 3 & 3 & 3 \\
\hline 2007 & 1 & 1 & 1 & 1 & 3 & 3 & 3 & 3 \\
\hline 2008 & 8 & 8 & 8 & 1 & 1 & 1 & 1 & 3 \\
\hline 2009 & 6 & 6 & 8 & 6 & 3 & 3 & 1 & 3 \\
\hline 2010 & 11 & 1 & 8 & 1 & 3 & 3 & 1 & 3 \\
\hline 2011 & 8 & 1 & 8 & 1 & 1 & 3 & 1 & 3 \\
\hline Classes (no.) & 5 & 5 & 4 & 3 & 2 & 2 & 2 & 1 \\
\hline Attribute* & 6 & 6 & 5 & 5 & 4 & 1 & 3 & 1 \\
\hline
\end{tabular}

*Attributes: 1, Permanent; 2, Stable; 3, Change; 4, Stable in the first years; 5 , Stable in the last years; 6 , Unspecified. aggregation groups the final number of classes obtained for both pixels were identical. This difference in LCC variability over the years influences the characterization of each pixel. This was the case for P1 and P2 which were classified as unspecified pixels using 15 LCC, but when using four classes they were classified as stable in the first years (P1) and permanent (P2) pixels.

Figure 10 presents the classified images for the year 2000, using the four groups of classes. The land cover maps, obtained using ED and DTW classifiers, presented slight differences, instead of what happens when using 15 classes (Figure 6). Superimposing the ED and DTW land cover maps, the percentages of agreement obtained were $74.3 \%$ and $92.5 \%$ using 15 and four classes, respectively. In Figure 10 it is possible to clearly identify the pixels with lower NDVI values (blue), such as water spots. The largest area of Rondonia was classified as group C (CETF, PSF, MFDE, PFS) using four classes, and as CETF using 15 LCC (Figure 6). These results demonstrate the consistency of the land cover maps before and after the aggregation of classes.

Table 6 presents the fraction of pixels classified in each attribute (defined in Table 3 and Figure 3), using the approaches previously evaluated. The number of pixels classified as permanent over the 13-year period increased considerably with the aggregation of the 15 classes. Furthermore, the number of pixels unspecified was greatly reduced. The results presented in Table 6 reinforce the idea that using the profiles from 2000 to classify all the years reduces the differences on the training profiles and, consequently, more similarity between the classification images over the years is achieved. Reducing the number of initial classes, aggregating the most similar, reduces the variability in the LCC over the years, providing more similar classification results between years and classifiers.

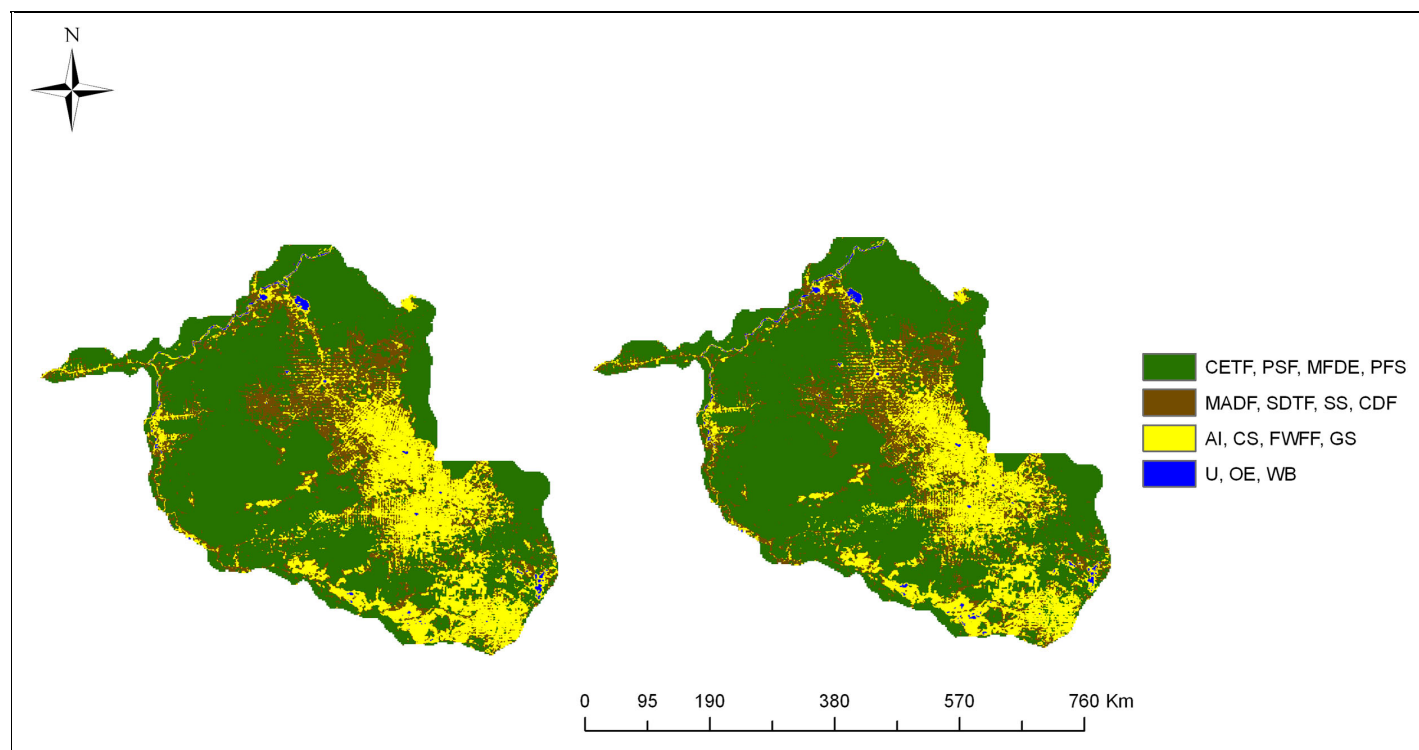

Figure 10. Classified images for the year 2000, using four groups of classes and using the Euclidean Distance (left) and Dynamic Time Warping (right) as classifiers. (See Table 2 for definitions of acronyms.) 


\section{Evaluation of the classification results using the PRODES data}

To evaluate the classification results obtained with the proposed methodology the PRODES data were used as a reference. Figure 11 (left) presents the classified maps for Rondonia obtained for 2000 and 2011 using the PRODES data. In both maps, the main region of Rondonia was classified as forest and it is easy to identify the water-covered area, in particular the area in the upper right corner of the images. The deforestation has increased considerably between 2000 and 2011, occupying the biggest area of the central region of Rondonia.

To compare the ED and DTW land cover changes between 2000 and 2011 with the reference (PRODES) data, a reclassification was made aggregating the 15 initial
LCC in three main classes: forest (enclosing the classes characterizing any type of forest vegetation (CETF, CDF, SDTF, PSF, MADF, MFDE, FWFF)), nonforest (AI, CS, GS, PFS, SS, U) and hydrography (WB, OE). The results of this reclassification, available in Figure 11, show coherent results between ED, DTW, and PRODES land cover maps. In both cases, the majority of Rondonia was classified as forest and the water spot in the upper right corner can be easily identified. For the new ED and DTW land cover maps, the percentage of pixels classified at each class was determined and compared with the PRODES data results (Table 7). The nonforest and deforestation classes of PRODES (reference) land cover maps were aggregated in a single class (nonforest). The results obtained based on the ED and DTW methodologies were consistent with those obtained from the reference data. The forest class occupies

Table 6. Fraction of pixels (\%) classified per attribute from 1999 to 2011.

\begin{tabular}{|c|c|c|c|c|c|c|c|c|}
\hline \multirow[b]{2}{*}{ Attribute } & \multicolumn{4}{|c|}{15 classes } & \multicolumn{4}{|c|}{4 classes } \\
\hline & ED & DTW & $\mathrm{ED}^{*}$ & DTW* & ED & DTW & $\mathrm{ED}^{*}$ & DTW* \\
\hline 1 - Permanent & 1.51 & 0.67 & 18.97 & 9.81 & 36.3 & 37.18 & 68.80 & 65.18 \\
\hline $2-$ Stable & 6.53 & 3.68 & 8.43 & 10.30 & 5.22 & 5.60 & 1.65 & 2.58 \\
\hline 3 - Change & 0.43 & 0.38 & 0.51 & 0.59 & 3.54 & 4.02 & 4.00 & 3.00 \\
\hline $4-$ Stable in the first years & 12.69 & 9.03 & 13.27 & 13.17 & 29.1 & 28.13 & 9.51 & 11.08 \\
\hline 5 - Stable in the last years & 13.70 & 18.37 & 15.26 & 22.55 & 8.02 & 8.24 & 8.64 & 8.71 \\
\hline 6 - Unspecified & 65.14 & 67.88 & 43.56 & 43.59 & 17.7 & 16.83 & 7.39 & 9.45 \\
\hline
\end{tabular}

*Profiles from 2000.

Note: ED, Euclidean Distance; DTW - Dynamic Time Warping.

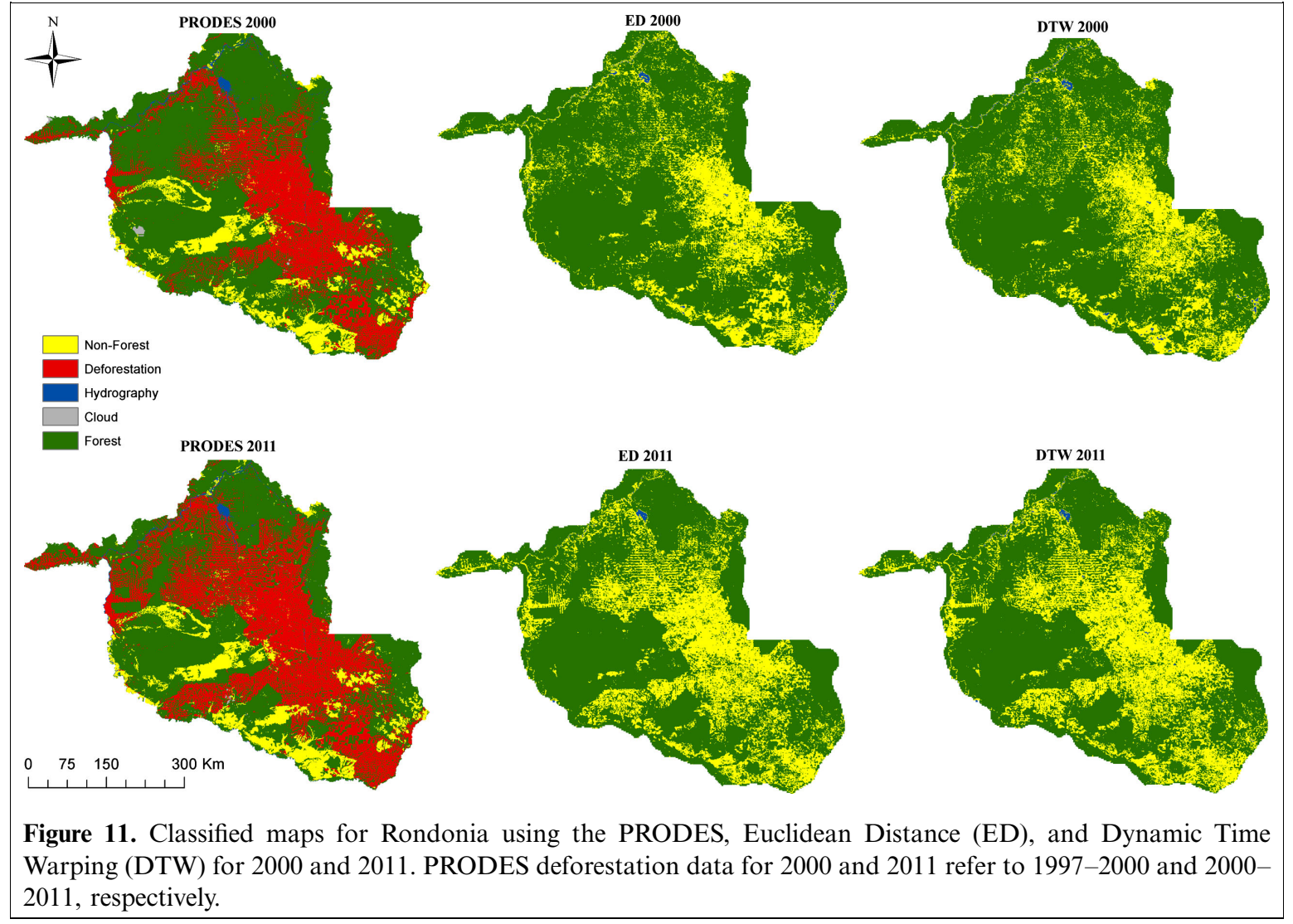


Table 7. Percentage of pixels classified at each class, using PRODES, ED, and DTW classifications for the years 2000 and 2011.

\begin{tabular}{llcccc}
\hline & Year & $\begin{array}{c}\text { Forest } \\
(\%)\end{array}$ & $\begin{array}{c}\text { Nonforest } \\
(\%)\end{array}$ & $\begin{array}{c}\text { Hydrography } \\
(\%)\end{array}$ & $\begin{array}{c}\text { Clouds } \\
(\%)\end{array}$ \\
\hline PRODES & 2000 & 62.96 & 36.09 & 0.77 & 0.18 \\
& 2011 & 53.01 & 46.15 & 0.78 & 0.07 \\
\hline Euclidean & 2000 & 77.76 & 21.83 & 0.41 & - \\
Distance & 2011 & 69.36 & 30.47 & 0.18 & - \\
(ED) & $2011^{*}$ & 65.50 & 34.14 & 0.36 & - \\
\hline Dynamic & 2000 & 77.99 & 21.46 & 0.54 & - \\
Time & 2011 & 67.71 & 32.03 & 0.25 & - \\
Warping & $2011^{*}$ & 68.38 & 31.26 & 0.36 & - \\
(DTW) & & & & & \\
\hline
\end{tabular}

*Profiles from 2000.

the majority of Rondonia, always higher than $53 \%$ areal coverage. The reference data presented a $9.95 \%$ decrease in the forest area, due to the increase of deforestation in the Rondonia region between the years 2000 and 2011 (Figure 11, left). The same conclusion was verified using the ED and DTW classifications, where a decrease (increase) of around $10 \%$ was verified in the forest (nonforest) class (Figure 11). The variability between hydrography can be due to the fact that the urban class (considered as nonforest) was sometimes classified as hydrography due to the low NDVI values and similar profile with WB and OE classes.

\section{Conclusions}

A new approach was proposed for land cover classification and land cover map updating based exclusively on temporal series data acquired by EOS. The approach was illustrated with a practical test using SPOT VGT data from 1999 to 2011 in the Brazilian Amazon. The GLC2000 was used as a reference to select 15 distinct LCC in the SPOT VGT images of Rondonia.

Maps of land cover changes for 1999-2011 were obtained using two classifiers: one that represents a time-rigid measure (ED) and another that represents a time-flexible measure (DTW). The similarity between some NDVI profiles had influenced the classification results, leading to some differences between the ED and DTW land cover maps, particularly in the eastern and western regions of Rondonia.

The noise due to the cloud contamination (especially from November to February) and the characteristics of the study area makes it difficult to classify 15 LCC in the Amazon region. Thus, the 15 initial LCC were gradually aggregated, joining the most similar, until only four final broad classes remained. The land cover variability over time was evaluated by making a pixel-by-pixel analysis. Each pixel was classified as permanent, stable, change, stable in the first years, stable in the last years, and unspecified using a criteria based on the number of identical classes from 1999 to 2011. The maps of land cover changes obtained using 15 and four LCC presented coherent results. As expected, the reduction of the number of classes allowed higher similarity over the years.

The PRODES data were used to evaluate the results of the ED and DTW classifications for the years 2000 and 2011. The ED and DTW land cover maps showed consistent results comparing with PRODES data, which proves that this approach is capable to produce accurate land cover maps for Rondonia, using exclusively temporal series data.

\section{Acknowledgments}

The authors would like to thank Flemish Institute for Technological Research (VITO) for the SPOT VEGETATION images, and also to the Global Vegetation Monitoring Unit of the European Commission Joint Research Centre, for providing access to the GLC2000. A. Rodrigues would like to thank to Fundação para a Ciência e a Tecnologia (FCT) for the Doctoral Grant (SFRH/BD/ 62189/2009). D. Furlan would like to thank to the Santander Scholarship Program for International Mobility and to the Research Foundation of the State of São Paulo - FAPESP (2010/02228-0), who supported the research period spent at the University of Porto.

\section{References}

Agrawal, R., Faloutsos, C., and Swami, A. 1993. Efficient similarity search in sequence databases. Lectures Notes in Computer Science, Vol. 730, pp. 69-84.

Agrawal, R., Lin, K., Sawhney, H.S., and Shim, K. 1995. Fast similarity search in the presence of noise, scaling, and translation in times-series databases. Proceedings of the $21^{\text {st }}$ International Conference on Very Large Data Bases, pp. 490-501.

Alves, D.S., Morton, D.C., Batistella, M., Roberts, D.A., and Souza Jr., C. 2009. The changing rates and patterns of deforestation and land use in Brazilian Amazonia. Geophysical Monograph Series, Vol. 186, pp. 11-23.

Alves, D.S., Pereira, J.L.G., De Sousa, C.L., Soares, J.V., and Yamaguchi, F. 1999. Characterizing landscape changes in central Rondonia using Landsat TM imagery. International Journal of Remote Sensing, Vol. 20, No. 14, pp. 2877-2882. doi: 10.1080/014311699211859.

ANA - Agência Nacional De Águas (Brasil). Sistemas de Informações Hidrológicas: http://hidroweb.ana.gov.br/HidroWeb [Accessed 7 March 2012].

Asner, G.P., Keller, M., Lentini, M., Merry, F., and Souza Jr., C. 2009. Selective logging and its relation to deforestation. Geophysical Monograph Series, Vol. 186, pp. 25-42.

Ballester, M.V.R., Victoria, D.C., Krusche, A.V., Coburn, R., Victoria, R.L., Richey, J.E., Logsdon, M.G., Mayorga, E., and Matricardi, E. 2003. A remote sensing/GIS-based physical template to understand the biogeochemistry of the Ji-Parana river basin (Western Amazonia). Remote Sensing of Environment, Vol. 87, No. 4, pp. 429-445. doi: 10.1016/j.rse.2002.10.001.

Berndt, D.J., and Clifford, J. 1994. Using Dynamic Time Warping to find patterns in time series. In Workshop on Knowledge Discovery in Databases, Seattle, USA, pp. 359-370. 
Braswell, B.H., Hagen, S.C., Frolking, S.E., and Salas, W.A. 2003. A multivariable approach for mapping sub-pixel land cover distributions using MISR and MODIS: Application in the Brazilian Amazon region. Remote Sensing of Environment, Vol. 87, pp. 243-256. doi: 10.1016/ j.rse.2003.06.002.

Brown, J.C., Jepson, W.E., Kastens, J.H., Wardlow, B.D., Lomas, J.M., and Price, K.P. 2007. Multitemporal, moderate-spatial-resolution remote sensing of modern agricultural production and land modification in the Brazilian Amazon. GIScience \& Remote Sensing, Vol. 14, No. 2, pp. 117-148. doi: 10.2747/1548-1603.44.2.117.

Carreiras, J.M.B., Pereira, J.M.C., Shimabukuro, Y.E., and Stroppiana, D. 2003. Evaluation of compositing algorithms over the Brazilian Amazon using SPOT-4 Vegetation data. International Journal of Remote Sensing, Vol. 24, No. 17, pp. 3427-3440. doi: 10.1080/0143116021000021251.

Chu, S., Keogh, E., Hart, D., and Pazzani, M. 2002. Iterative deepening Dynamic Time Warping for time series. In Proceedings of the 2nd SIAM International Conference on Data Mining, Maebashi City, Japan.

Dale, V.H., O’Neill, R., Southworth, F., and Pedlowsky, M. 1994. Modeling effects of land management in the Brazilian Amazonian settlement of Rondonia. Conservation Biology, Vol. 8, No. 1, pp. 196-206. doi: 10.1046/j.1523-1739.1994.08010196.x.

Da Rocha, H.R, Goulden, M.L., Miller, S.D., Menton, M.C., Pinto, L.D.V.O, De Freitas, H.C., and Figueira, A.M.S. 2004. Seasonality of water and heat fluxes over a tropical forest in eastern Amazon. Ecological Application, Vol. 14, No. 4, Supplement, pp. S22-S32. doi: 10.1890/02-6001.

Das, G., Lin, K., Mannila, H., Renganathan, G., and Smyth, P. 1998. Rule discovery from time series. Proceedings of the 4th International Conference on Knowledge Discovery and Data Mining, pp. 16-22.

Debregeas, A., and Hebrail, G. 1998. Interactive interpretation of Kohonen maps applied to curves. Proceedings of the 4th International Conference on Knowledge Discovery and Data Mining, pp. 179-183.

Eva, H.D., Miranda, E.E., Di Bella, C.M., Gond, V., et al. 2002. Vegetation map of South America. Joint Research Centre - EUR20159, Office for Publications of the European communities, Luxembourg.

Eva, H.D., Belward, A.S., Miranda, E.E., et al. 2004. A land cover map of South America. Global Change Biology, Vol. 10, pp. 31-744. doi: 10.1111/j.1529-8817.2003.00774.x.

Eva, H.D., Gallego, J., Strahler, et al. 2006. Validation of the global land cover 2000 map. IEEE Transactions on Geoscience and Remote Sensing, Vol. 44, No. 7, pp. 1728-1739. doi: 10.1109/TGRS.2006.864370.

Faloutsos, C., Ranganathan, M., and Manolopoulos, Y. 1994. Fast subsequence matching in time-series databases. ACM SIGMOD Record, Vol. 23, No. 2, pp. 419-429. doi: 10.1145/191843.191925.

Fujisaka, S., Bell, W., Thomas, N., Hurtado, L., and Crawford, E. 1996. Slash-and-burn agriculture, conversion to pasture, and deforestation in two Brazilian Amazon colonies. Agriculture, Ecosystems \& Environment, Vol. 59, No. 1-2, pp. 115-130. doi: 10.1016/0167-8809(96) 01015-8.

Gonsamo, A., and Chen, J.M. 2011. Evaluation of the GLC2000 and NALC2005 land cover products for LAI retrieval over Canada. Canadian Journal of Remote Sensing, Vol. 37, No. 3, pp. 302-313. doi: 10.5589/m11-039.

Houghton, P.A., Skole, D.L., Nobre, C.A., Hackler, J.L., Lawrence, K.T., and Chomentowski, W.H. 2000. Annual fluxes of carbon from deforestation and regrowth in Brazilian Amazon. Nature, Vol. 403, pp. 301-304. doi: 10.1038/35002062.

Keogh, E.J., Chakrabarti, K., Pazzani, M.J., and Mehrotra, S. 2001. Dimensionality reduction for fast similarity search in large time series databases. Knowledge and Information Systems, Vol. 3, No. 3, pp. 263286. doi: 10.1007/PL00011669.

IBGE (Instituto Brasileiro de Geografia e Estatistica) 2013. Available at http://ibge.gov.br/home/ [Accessed 16 February 2013].

INPE 2000. Monitoring of the Brazilian Amazon forest by satellite 19992000. Available at http://mtc-m18.sid.inpe.br/col/dpi.inpe.br/lise/2001/ 05.16.09.55/doc/html/capa.htm [Accessed 16 February 2013].

Li, G., Lu, D., Moran, E., and Hetrick, S. 2012. Land-cover classification in a moist tropical region of Brazil with Landsat TM imagery. International Journal of Remote Sensing, Vol. 32, No. 23, pp. 8207-8230. doi: 10.1080/ 01431161.2010 .532831$.

Loveland, T.R., Reed, B.C., Brown, J.F., Ohlen, D.O., Zhu, Z., Yang, L., and Merchant, J.W. 2000. Development of a global land cover characteristics database and IGBP DISCover from $1 \mathrm{~km}$ AVHRR data. International Journal of Remote Sensing, Vol. 21, pp. 1303-1330. doi: $10.1080 / 014311600210191$.

Malhi, Y., Pegoraro, E., Nobre, A.D., Pereira, M.G.P., Grace, J., Culf, A.D., and Clement, R. 2002. Energy and water dynamics of a central Amazonian rain forest. Journal of Geophysical Research: Atmospheres, Vol. 107, No. D20, pp. LBA 45-1-LBA 45-17. doi: 10.1029/2001JD000623.

Moran, E.F. 1993. Deforestation and land use in the Brazilian Amazon. Human Ecology, Vol. 21, No. 1, pp. 1-21. doi: 10.1007/BF00890069.

Press, W.H., Teukolsky, S.A., Vetterling, W.T., and Flannery, B.P. 2007. Numerical Recipes: The Art of Scientific Computing, 3rd Edition. Cambridge University Press, pp. 766-772.

Pedlowski, M.A., Dale, V.H., Matricardi, E.A.T., and Filho, E.P.S. 1997. Patterns and impacts of deforestation in Rondonia, Brazil. Landscape and Urban Planning, Vol. 38, No. 3-4, pp. 149-157. doi: 10.1016/S01692046(97)00030-3.

PRODES (Programa de Cálculo do Desflorestamento da Amazônia) 2013. Available at http://www.obt.inpe.br/prodes/index.php [Accessed 16 January 2013].

Reed, G.F., Lynn, F., and Meade, B.D. 2002. Use of coefficient of variation in assessing variability of quantitative assays. Clinical and Vaccine Immunology, Vol. 9, No. 6, pp. 1235-1239. doi: 10.1128/CDLI.9.6.12351239.2002.

Rodrigues, A., Marçal, A.R.S., and Cunha, M. 2013. Identification of land cover changes on a continental scale using NDVI time-series from SPOT VEGETATION. International Journal of Remote Sensing, Vol. 34, No. 22, pp. 8028-8050.

Rouse, J.W., Haas, R.H., Schell, J.A., and Deering, D.W. 1973, Monitoring vegetation systems in Great Plains with ERST. Proceedings of the 3rd ERTS Symposium, NASA SP-351, 10-14 December 1973, Washington, DC (US Government printing office), pp. 309-317.

VITO (Free SPOT VEGETATION products) 2012. Available at http://free. vgt.vito.be/ [Accessed 10 August 2012].

Wardlow, B.D., and Egbert, S.L. 2008. Large-area crop mapping using time-series MODIS 250m NDVI data: An assessment for the U.S. Central Great Plains. Remote Sensing of Environment, Vol. 112, pp. 1096-1116. doi: 10.1016/j.rse.2007.07.019. 